\title{
What Does Cerebral Oxygenation Tell Us About Central Motor Output?
}

\author{
Nicolas Bourdillon and Stéphane Perrey \\ Movement To Health (M2H), Montpellier-1 University, Euromov
}

France

\section{Introduction}

Since the fifth Century Athens, when Hippocrates identified the brain as the source of thought and understanding, humanity has been preoccupied with its functions. Anatomical descriptions have been brought to modernity by Andreas Vesalius in the sixteenth century (Vesalius, 1543) while underlying mechanisms have awaited the discovery of "bioelectricity" by Luigi Galvani in the eighteenth century to emerge (Galvani, 1791). In the nineteenth century, famous physicians such as Paul Broca or Carl Wernicke have demonstrated the role of the brain in cognitive tasks, studying patients with neurological disorders (Broca, 2004; Wernicke, 1894). From the late twentieth century to present day, neuroimaging techniques have allowed explorations in healthy subjects providing very precise locations of brain regions involved in cognitive and motor functions.

For the advancement of theory it is essential to acknowledge the strengths and limitations of available neuroimaging techniques so that converging evidence on the basis of multiple modes of investigation can be brought to bear on current controversies in the literature. Electroencephalography (EEG) was chronologically the first technique to open the way to the study of brain functions in exercising subjects (Swartz and Goldensohn, 1998). While one of the most direct methods to non-invasively measure the electrical signal arising from the synchronous firing of neurons, spatial resolution and lack of information from areas deeper than the cortex are its main limitations. Magnetoencephalography (MEG) is also a direct measure of the electrical activity of neurons and has a better spatial resolution as compared with EEG. However, the lack of detection in deep brain structures and the threshold detection (at least 50,000 neurons active simultaneously are needed) make MEG main disadvantages (Shibasaki, 2008). Functional imaging such as positron emission tomography (PET), single photon emission computed tomography (SPECT) and functional magnetic resonance imaging (fMRI) overcome the EEG and MEG limitations as they can detect neuronal activity as deep in the brain as experimenters desire (Cui et al., 2011; Villringer, 1997). However, the measure is indirect as it relies on blood supply for fMRI or on radioactive tracers for PET and SPECT (Jantzen et al., 2008; Tashiro et al., 2008). Additionally, except for EEG, the experimental environments of the earlier described techniques are very restricting with regards to physical exercise. Subjects and experimenters are limited to sit or laid positions and to breathe, eye, wrist and ankle movements. Actually, in vivo determination of brain functions in humans requires flexible, accessible and rapid monitoring techniques (Kikukawa et al., 2008; Perrey, 2008; 
Rasmussen et al., 2007). Near infrared spectroscopy (NIRS) is perhaps the technique which best gathers these qualities; which may account for the increasing popularity of NIRS among research teams in recent years.

\section{Near infrared spectroscopy in humans}

As suggested by its name, the NIRS technique relies on red and infrared light diffusion through the living tissues. Physically, NIRS systems consist of numerous probes designed to be attached directly on the skin, over the area(s) to explore. Either optical fibres or regular electrical wires link the probes to a dedicated hardware, which in turn feeds a computer with experimental data. Probes are made of light transmitters and light receivers; the light power emission, the receiver gain and the interoptode distance can be adapted to match with the characteristics and depth of the areas under investigation. However, those three parameters necessarily come as inputs for the NIRS dedicated software which drives the record session.

\subsection{Principles of physics underlying the NIRS technique}

Back in the eighteenth century, the brilliant French scientist Pierre Bouguer (1698-1758) is probably the true father of photometry (Bouguer, 1729). The goal of his publication entitled "Essais sur la gradation de la lumière" in 1729 was to quantify how much light is lost when travelling through a given atmospheric layer. To achieve his work, he empirically characterizes materials with an optical density (OD) as follows:

$$
\mathrm{OD}=\log \left(\frac{\mathrm{I}_{0}}{\mathrm{I}}\right)
$$

where $\mathrm{I}_{0}$ is the intensity of the incident light and I the intensity of the transmitted light. More than one hundred years later, the German scientist August Beer (1825-1863), based on JeanHenri Lambert's (1728-1777) and Pierre Bouguer's works, published "Einleitung in die höhere Optik" (1853), where he defined transmittance of light rather than its loss when travelling through a tissue (Beer, 1853). What is now known as the Beer-Lambert's law is a different version of Bouguer's idea (eq.1). The Beer-Lambert's law (eq.2) states that there is a logarithmic dependence between the transmission of light (T) and the product of the absorption coefficient of the substance the light travelled through $(\alpha)$ and the distance travelled by the light (also called path length, l).

$$
\mathrm{T}=10^{\propto l}
$$

In turn, the absorption coefficient a depends on the product of the extinction coefficients $(\varepsilon)$ and the concentration (c) of the absorbers in the material. In liquids, the Beer-Lambert's law is often written as follows:

$$
\mathrm{T}=10^{\varepsilon \mathrm{cl}}
$$

Equations 1 and 3 imply that there is a linear relationship between Bouguer's optical density and the concentration of species in the material explored:

$$
\mathrm{OD}=\varepsilon \mathrm{cl}
$$


From equation 4 (illustrated by fig.1), the main idea of NIRS is to compute the concentration of species (c) by measuring the OD according to Bouguer's definition (eq.1) and, inserting the a priori known extinction coefficients for species and the path length of light (eq. 4).

Panel A

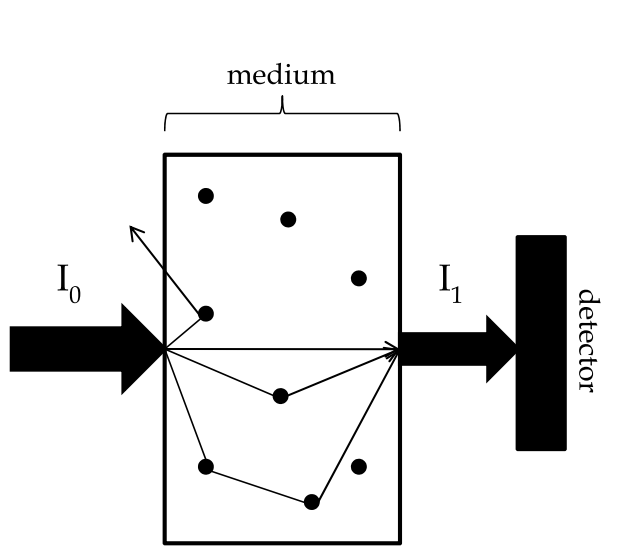

Panel B

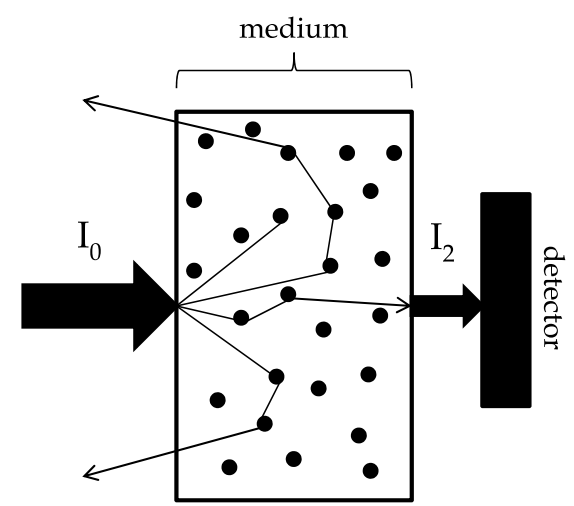

Fig. 1. Illustration of the Beer-Lambert's law. In panel A, the medium has a low OD (transmitted light $\mathrm{I}_{1}$ is close to incident light $\mathrm{I}_{0}$ ); the concentration of absorbing species is low. In panel $\mathrm{B}, \mathrm{OD}$ is higher (larger difference between $\mathrm{I}_{2}$ and $\mathrm{I}_{0}$ than between $\mathrm{I}_{1}$ and $\mathrm{I}_{0}$ ), so is the concentration of absorbing species.

\subsection{Application of NIRS to living tissues}

At least six conditions have to be fulfilled in order for the Beer-Lambert's law to be valid:

- the absorbers must act independently from each others;

- $\quad$ the absorbing medium must be homogeneous in the interaction volume;

- $\quad$ the absorbing medium must not scatter the radiation;

- the incident radiation must consist of parallel rays, each travelling the same length in the medium;

- the incident radiation must be monochromatic;

- $\quad$ the incident radiation must not influence the atoms in the medium.

Living tissues, especially in humans, are doubtlessly among the most structured and complex in the universe. Their characteristics do not match with the Beer-Lambert's law prerequisites on numerous points. Therefore, the modified Beer-Lambert's law has to be applied in NIRS. As stated in the fifth point of the prerequisites, the incident light must be monochromatic (i.e. only one wavelength $\lambda$ ). In human tissues, lots of chemical species absorb light and account for its loss when travelling. However, there is a range of wavelengths at which light travel is much facilitated. Intuitively, when, in a dark environment, one looks at a flashlight through his finger or his hand, red is invariably the dominant colour. The physical explanation is that the red light travel through the human tissues is easier than for any other wavelengths. Implicitly, in the red portion of the visible 
light, there are a limited number of chemical species which are responsible for the majority of light absorption and diffusion. These species are known to give its colour to the tissue and have been judiciously named chromophores. In human tissues, it is well known that haemoglobin is responsible for the colour given to tissues; in physics, haemoglobin is the chromophore whose concentration can be measured using Bouguer's idea.

\subsubsection{The chromophores}

Haemoglobin is a metalloprotein which transports $98 \%$ of the oxygen in most vertebrates' blood. When oxygen binds to the iron complex, it causes the iron ion to move back, and changes the optical properties of the molecule. At the human scale the phenomenon is perceptible and results in the long standing view that the red blood is filled-up with oxygen while the blue one has lost the majority of its initial quantity of oxygen. In physics, it can be considered that there are two distinct chromophores: oxygenated haemoglobin $\left(\mathrm{O}_{2} \mathrm{Hb}\right)$ and deoxygenated haemoglobin $(\mathrm{HHb})$. Therefore, according to Bouguer's idea one can compute the concentration of oxy and deoxyhaemoglobin in a tissue by measuring the changes in OD (eq. 4). However, the OD in human tissues is not strictly dependant on haemoglobin. In an imaginary case where there would be no haemoglobin in the explored area, the tissue would still absorb light. Consequently, eq. 4 should be rewritten as:

$$
\mathrm{OD}_{(\lambda)}=\varepsilon_{(\lambda)} \cdot c \cdot 1+\mathrm{ODr}_{(\lambda)}
$$

where ODr is the y-intercept of the linear relation and denotes the OD of the living tissue when there is no haemoglobin. $\lambda$ denotes the chosen wavelength for the monochromatic light.

\subsubsection{Two wavelengths}

The Beer-Lambert's law states that the measured optical density is the sum of the absorbance of the two chromophores. Eq. 5 becomes eq. 6 with the two chromophores appearing:

$$
\mathrm{OD}_{(\lambda)}=\varepsilon_{\mathrm{O} 2 \mathrm{Hb}(\lambda)} \cdot \mathrm{c}_{\mathrm{O} 2 \mathrm{Hb}} \cdot 1+\varepsilon_{\mathrm{HHb}(\lambda)} \cdot c_{\mathrm{HHb}} \cdot 1+\mathrm{ODr}_{(\lambda)}
$$

There are two unknowns in eq. 6 (ie. $\mathrm{CO}_{2} \mathrm{Hb}$ and $\mathrm{C}_{\mathrm{HHb}}$ ). Thus, two equations are needed to solve the system. The two equations are provided by firing at two different wavelengths $\lambda_{1}$ and $\lambda_{2}$.

$$
\left\{\begin{array}{c}
\mathrm{OD}_{(\lambda l)}=\varepsilon_{\mathrm{O} 2 \mathrm{Hb}(\lambda 1)} \cdot \mathrm{c}_{\mathrm{O} 2 \mathrm{Hb}} \cdot 1+\varepsilon_{\mathrm{HHb}(\lambda 1)} \cdot c_{\mathrm{HHb}} \cdot 1+\mathrm{ODr}_{(\lambda l)} \\
\mathrm{OD}_{(\lambda 2)}=\varepsilon_{\mathrm{O} 2 \mathrm{Hb}(\lambda 2)} \cdot \mathrm{c}_{\mathrm{O} 2 \mathrm{Hb}} \cdot 1+\varepsilon_{\mathrm{HHb}(\lambda 2)} \cdot c_{\mathrm{HHb}} \cdot 1+\mathrm{ODr}_{(\lambda 2)}
\end{array}\right.
$$

The main idea is that one needs as many wavelengths as there are chromophores in the investigated area. Only one equation is exposed further down this line for clarity purpose. Note that NIRS systems perform every computation to solve the systems of equations.

\subsubsection{Application of the modified Beer-Lambert's law}

Since physiologists use NIRS to compute the haemoglobin concentration, the modified BeerLambert's law is then written:

$$
c=\frac{\left(\mathrm{OD}_{(\lambda)}-\mathrm{ODr}_{(\lambda)}\right)}{\varepsilon_{(\lambda)} \cdot 1}
$$


In eq. $8, \mathrm{OD}$ is measured using Bouguer's idea (eq.1), $\varepsilon$ is known from the physicists who are able to measure it (fig.2), ODr and 1 are unknown but necessary to the computation of c.

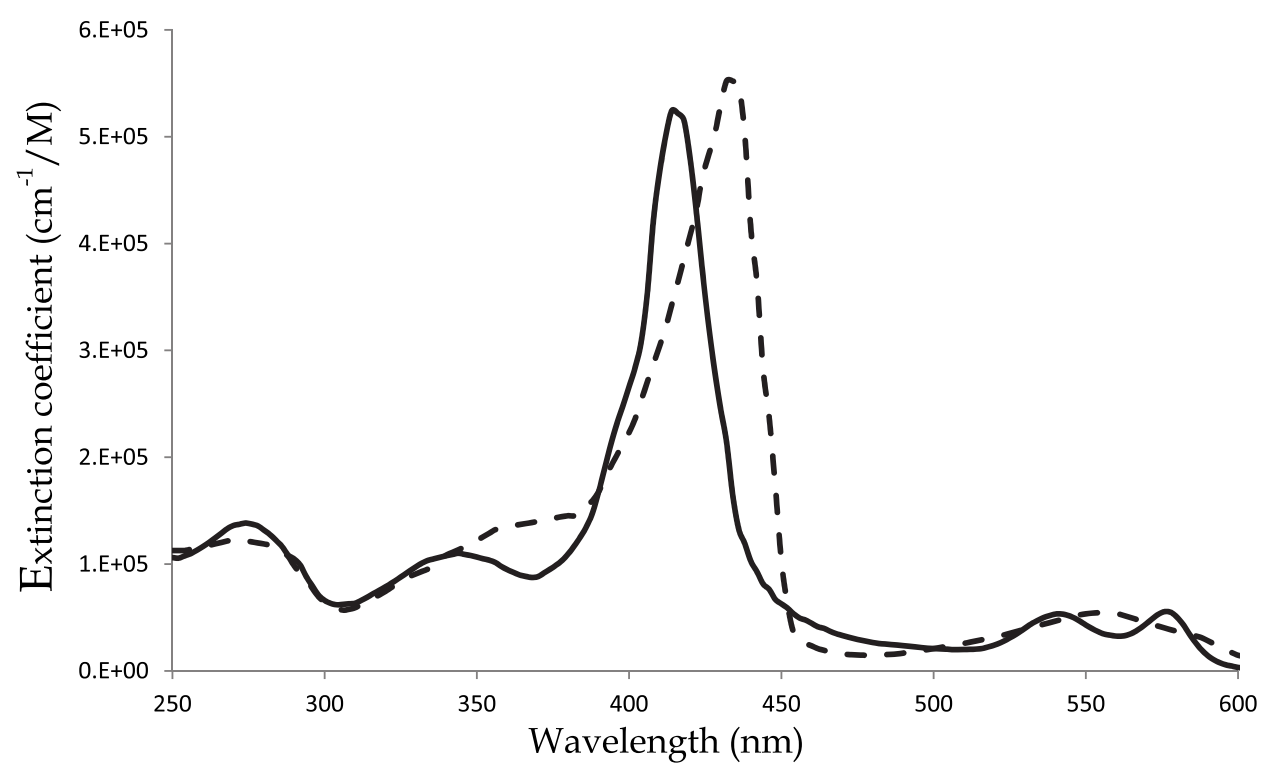

Fig. 2. Molar extinction coefficient for haemoglobin in water. $\mathrm{O}_{2} \mathrm{Hb}$ : plain line; $\mathrm{HHb}$ : dashed line; $x$ axis: wavelength $(\lambda)$ in $\mathrm{nm}$; y axis: extinction coefficient $(\varepsilon)$ in $\mathrm{cm}^{-1} / \mathrm{M}$. Data compiled by Scott Prahl (Prahl, 2008).

ODr is not expected to change radically in a short lap of time. In other words, it is considered constant between two light impulsions a few tenths of seconds away. Therefore, considering two light impulsions at $\mathrm{t}_{0}$ and $\mathrm{t}_{1}$, it is possible to write:

$$
c_{\mathrm{t} 0}-\mathrm{c}_{\mathrm{t} 1}=\frac{\left(\mathrm{OD}_{(\lambda) \mathrm{t} 0}-\mathrm{ODr}_{(\lambda)}\right)}{\varepsilon_{(\lambda)} \cdot 1}-\frac{\left(\mathrm{OD}_{(\lambda) \mathrm{t} 1}-\mathrm{ODr}_{(\lambda)}\right)}{\varepsilon_{(\lambda)} \cdot 1}
$$

which simplifies into

$$
\mathrm{c}_{\mathrm{t} 0}-\mathrm{c}_{\mathrm{t} 1}=\frac{\left(\mathrm{OD}_{(\lambda) \mathrm{t} 0}-\mathrm{OD}_{(\lambda) \mathrm{t} 1}\right)}{\varepsilon_{(\lambda)} \cdot 1}
$$

Eq. 10 states that the concentration variations depend on the measured OD variations. The advantage of the subtraction in eq. 9 is to get rid of the unknown ODr. However, the absolute concentration of the chromophore becomes unknown as only a concentration difference (or variation) can be computed.

The last unknown parameter missing to compute the concentration variation is 1 , the path length of light between the transmitter and the receptor (fig. 3). Its measure is almost impossible due to the numerous interactions between the matter and the light in living tissues (Ijichi et al., 2005). Three methods are available to approach the path length: 
- $\quad$ the differential path length factor (DPF)

- the time of flight

- the Monte Carlo simulation

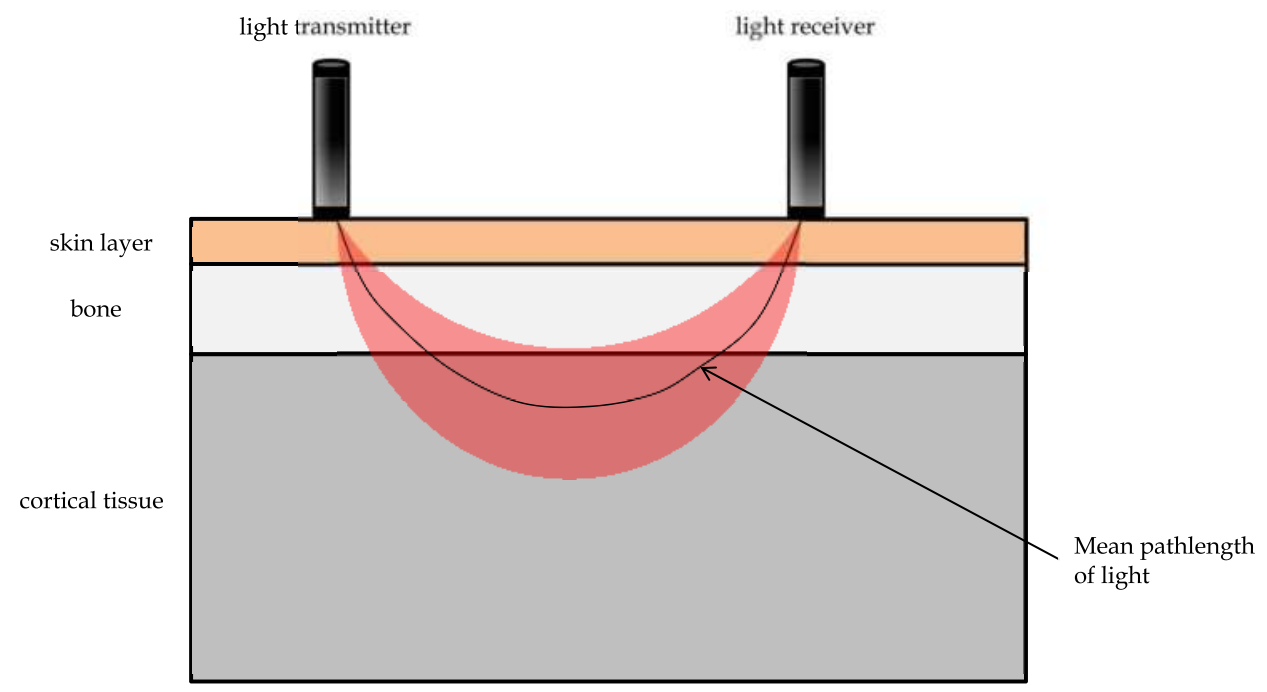

Fig. 3. Schematic representation of NIRS applied to human cerebral tissues. The mean path length of light represents the l.DPF in eq.11. Roughly, the maximum depth of the mean path length of light is believed to be half of the emitter to receiver distance.

The DPF method is doubtlessly the easiest to use but also the less precise and less satisfactory. Regrettably it is the most common method nowadays. In this method, 1 is considered the most direct way between the light transmitter and receptor, DPF is multiplied to 1 to lengthen the global path length, eq. 10 is then written:

$$
\Delta \mathrm{c}=\frac{\Delta \mathrm{OD}_{(\lambda)}}{\varepsilon_{(\lambda)} \cdot 1 . \mathrm{DPF}}
$$

DPF is arbitrarily set from abacus found in the literature. Only a few studies give the DPF, often as a function of age (Duncan et al., 1995; Essenpreis et al., 1993a; Essenpreis et al., 1993b; Firbank et al., 1993; Ijichi et al., 2005; Kohl et al., 1998a; Kohl et al., 1998b; Nolte et al., 1998; Pringle et al., 1999; Ultman and Piantadosi, 1991; van der Zee et al., 1992; Zhao et al., 2002). Another way to approach the path length of light is to measure the time of flight between the light transmitter and the receptor. The speed of light in the vacuum is used to compute the path length. This method is more precise than the DPF method but costly financially and in terms of load of computation. Billion of photons are detected by the receptor at each light impulsion. One of the advantages is the possibility to select the photons to study; the first detected photons have a priori a shorter path length, which means that they did not go deep into the tissues (Ferrante et al., 2009). The latest photons, which have a longer path length, went a priori deeper into the tissues and carry more information. Finally, the Monte Carlo simulation is a statistical method representing the distribution of energy in the explored volume. It is a way to assume the random path length 
of photons between the light transmitter and the receptor (Hiraoka et al., 1993; Simpson et al., 1998; Zhang et al., 2007a, b). This is the most precise method nowadays, usable with regular measurement devices but costly in terms of computation. The Monte Carlo method might be performed after the monitoring session as computers may not be powerful enough to ensure simultaneously proper recording of the data and Monte Carlo analysis (Avrillier et al., 1998a; Avrillier et al., 1998b). Roughly, for all methods the maximum depth of the mean path length of light is believed to be half of the emitter to receiver distance.

\section{Signal characteristics and interpretations}

NIRS data consist of oxy and deoxyhaemoglobin time series (Fig. 4 and Fig. 5), with sampling rate usually ranging from 2 to $20 \mathrm{~Hz}$, and occasionally above. Usual measurement sites exclude locations where large arteries or veins would be reachable by the NIRS light as experimenters are rather interested in tissue data. In the tissues, the light crosses three types of blood vessels:

- $\quad$ arterioles (diameter below $100 \mu \mathrm{m}$, average 20-30 $\mu \mathrm{m}$ )

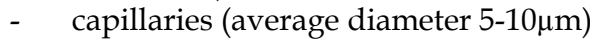

- venules (average diameter 8-30 $\mu \mathrm{m}$ )

NIRS signal is believed to originate in its major part from the venous compartment (approx. $70 \%$ ); however, vasomotion makes the part of each segment variable (Bourdillon et al., 2009; Peltonen et al., 2009). Briefly, capillaries form an extensive network which connects the arterial and venous sides of the vascular system. The blood flow through a given capillary bed strongly depends on the vascular tone of the parent arteriole and the pre-capillary sphincters. Both adjust the local blood flow to meet the physiological demands. Despite the smooth muscles of the arterioles and sphincters are connected to the sympathetic nervous system, the vascular tone is largely dependent on the local factors (Segal, 2005). Concerning the motor areas of the brain, it is generally assumed that, when activated, the neurons increase their firing rates to generate the motor command and thus increase their metabolic demands (Villringer, 1997). One of the consequences is to increase the local blood flow; this

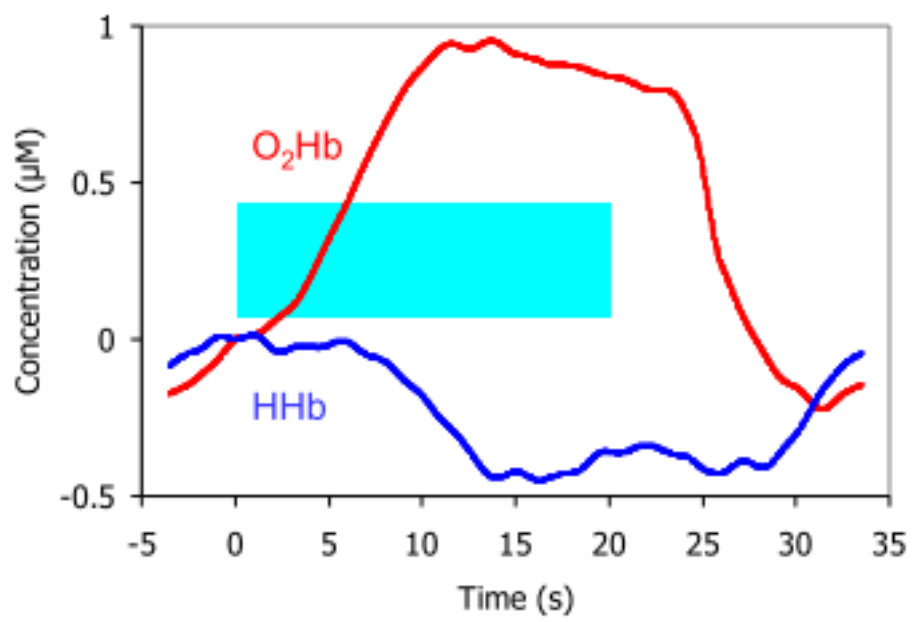

Fig. 4. Example of a NIRS signal pattern over the motor cortex during a 20 seconds lasting handgrip task (Wolf et al., 2007). 
phenomenon can be detected by NIRS. It is obvious that the NIRS measurements are indirect with regards to neuronal activity and rely on the assumption that the latter is coupled to blood supply. Moreover, NIRS measures the concentrations of oxy and deoxyhaemoglobin (the sum of both, Hbtot, giving a proxy of local blood volume), not the blood flow nor the oxygen consumption. Fig. 4 shows a typical NIRS record during a simple motor task (handgrip).

\subsection{Patterns}

Empirically, activation pattern in the motor cortex is identified as an increase in oxyhaemoglobin concomitant to a decrease in deoxyhaemoglobin (Fig. 4). The reasons which give the activation pattern such a shape are not fully elucidated (Dai et al., 2001; Harada et al., 2006; Matsuura et al., 2011). However, it is commonly thought that the vasodilation caused by the increase in metabolic demand from the firing neurons overcomes the needs in oxygen; which results in an apparent increase in tissue oxygenation as measured by NIRS (Franceschini and Boas, 2004; Gervain et al., 2011; Leff et al., 2011; Rooks et al., 2010; Shibasaki, 2008; Shibuya and Tachi, 2006). The amplitudes of changes in oxy and deoxyhaemoglobin within the motor cortex areas have been shown to be dependent on the force production: the stronger the push, the higher the oxyhaemoglobin (Shibuya and Tachi, 2006; Smith et al., 2003). However, at low levels of force, there might be no detection by the NIRS systems (at least $10 \%$ of maximal voluntary contraction needed); while at high levels (about $50 \%$ of maximal voluntary contraction and above) there might be no plateau but only a peak in oxyhaemoglobin (Ekkekakis, 2009). This type of activation pattern is valid only for steady systemic variables (ie. globally non moving body). The NIRS signal, as it comes from the circulatory system, is strongly dependent on the cardio-respiratory parameters. Modifications in cardiac output, autonomic nervous system balance, hormonal response,

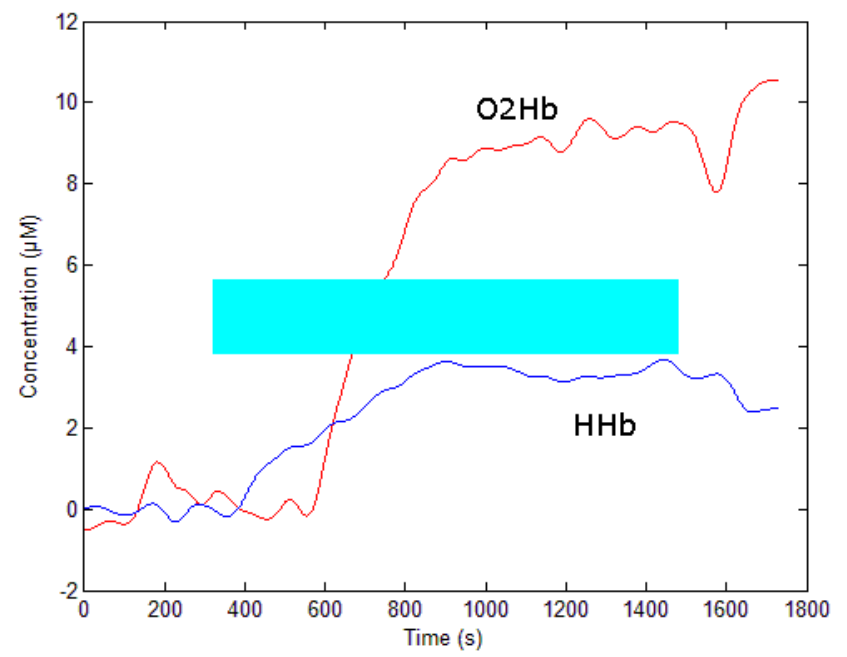

Fig. 5. Example of a NIRS signal pattern over the motor cortex during a high intensity whole body cycling exercise at a constant work rate from baseline level (warm up) at $600 \mathrm{~s}$.

Personal data. 
blood concentration in oxygen or carbon dioxide, baroreflexes and neural feedbacks from metabo and mecano receptors in the skeletal muscle potentially affect the vascular tone and thus the NIRS signal. Consequently, in subjects exercising at high metabolic rates (elevated oxygen consumption), with hyperventilation, hyper/hypocapnia and high cardiac output, the NIRS signal is rather dependant on systemic variables than on motor command (Pereira et al., 2007; Rasmussen et al., 2007). Fig. 5 shows a typical NIRS response from the motor cortex of a subject exercising on a cycloergometer above the ventilatory threshold for 20 minutes (Rooks et al., 2010; Rupp and Perrey, 2008). The amplitudes of the variations are way larger as compared with fig. 4 and the "activation pattern" is altered as there is no apparent decrease in deoxyhaemoglobin. In any case, the interpretation of the NIRS signals has to be modulated following the experimental design and the systemic conditions (Gervain et al., 2011; Rooks et al., 2010).

\subsection{Delay}

As shown in fig. 4 or fig. 5, there is a delay between the stimulus, the neural responses and the hemodynamic modifications as detected by the NIRS systems (Cui et al., 2010b; Yasui et al., 2010). If the NIRS signal depends on the motor command, the delay has been shown to range between 2 and 5 seconds (Fig. 4). In the case of fig. 5 the NIRS signal is rather dependant on systemic parameters (i.e. ventilation) and the delay ranges between 1 and 4 minutes. Such variations in delays are due to the facts that the NIRS records of cerebral hemodynamic parameters depend whether on the motor command or on systemic parameters, following the experimental design. To date, the time course analysis of NIRS signals has yet to be established, notably with regards to the transition periods and the experimental designs.

\subsection{NIRS computed indicators}

The only parameters measured by NIRS are the optical densities at two (or more) wavelengths as stated in the part 2.2.2 of this article. $\mathrm{O}_{2} \mathrm{Hb}$ and $\mathrm{HHb}$ are directly computed variables; the computer usually performs calculations during data acquisition. Afterwards, experimenters are using to computing other parameters from $\mathrm{O}_{2} \mathrm{Hb}$ and $\mathrm{HHb}$ to present NIRS data. Among the most often found parameters in the literature there are: the difference between $\mathrm{O}_{2} \mathrm{Hb}$ and $\mathrm{HHb}$ (usually abbreviated $\mathrm{O}_{2} \mathrm{Hbdiff}$ or Hbdiff); the tissue or capillary saturation (usually abbreviated $\mathrm{StO}_{2}$ or $\mathrm{ScO}_{2}$ ) and the tissue oxygenation index (TOI). TOI, $\mathrm{StO}_{2}$ and $\mathrm{ScO}_{2}$ are given by the simple formula:

$$
\mathrm{TOI}=\frac{\mathrm{O}_{2} \mathrm{Hb}}{\mathrm{O}_{2} \mathrm{Hb}+\mathrm{HHb}}
$$

These indicators are thought to summarize $\mathrm{O}_{2} \mathrm{Hb}$ and $\mathrm{HHb}$ signals and reflect tissue oxygenation. However, physical exercise results in a large heterogeneous increase in cerebral oxygenation (Rooks et al., 2010). It seems that the primary factor influencing this increase is the intensity of exercise, followed by the training status of the subjects, age, health status (i.e., patients vs. healthy subjects) and methodology.

\subsection{Pre-processing}

In most studies, NIRS data is pre-processed in order to improve the signal quality (Boas et al., 2004). The first step typically aims at removing noise (Gervain et al., 2011). The noise 
comes from the devices as well as from physiological parameters not a priori linked to the stimulation (eg. Exercise) and are thus undesirable (Nolte et al., 1998). This kind of noise is considered high frequency with regards to the frequencies of interest (Cui et al., 2010a). Low-pass filters are used to remove heart rate, blood pressure variations, breath, swallowing etc. Usually, the cut-off frequency ranges between 0.1 and $1 \mathrm{~Hz}$. Detrending is performed using a high-pass filter when NIRS signals slowly drift throughout the experimental session. High-pass filters usually range between 0.01 and $0.05 \mathrm{~Hz}$. However experimenters must care as the frequencies of interest could be part of this range. Finally, experimenters have several tools to choose from to remove movement artefacts. If possible set a marker during the experimental session when the subject moved his head is a good start. Retrospectively, the eye of the physiologist is the first tool which can be used. However, its somehow objective behaviour and its inability to treat large amounts of data make its main limits. Abrupt changes in the signals can be detected and corrected by algorithms (Lloyd-Fox et al., 2010; Wilcox et al., 2008). However, the thresholds must be defined carefully in order to preserve the changes that supposedly belong to the awaited hemodynamic response (Gervain et al., 2011).

\subsection{Data analysis}

Since NIRS is a relatively new technique for brain investigations, there is no standardised method to analyse data. Up to date, the only invariant is that different experimental designs require different analysis techniques.

In block-designed studies, experimenters are used to analysing time series by averaging multiple trials of the same condition. Mean variations and mean time courses are then obtained for each condition. The critical points of such techniques are the determination of the relevant windows of the time series and the baseline which it is compared to. Once determined, student t-test and analyses of variance are the most often used statistical methods.

More complex, three main freeware packages are downloadable and provide analysis methods derived from the BOLD signal of fMRI: HomER (Huppert et al., 2009), fOSA (Koh et al., 2007) and NIRS-SPM (Ye et al., 2009). The general linear model (GLM) and the statistical parametric mapping (SPM) offer the possibility to create three dimensional pictures of the brain, where activated/inhibited cortex areas are colour encoded (Friston et al., 1999; Plichta et al., 2007; Schroeter et al., 2004; Zarahn et al., 1997). In most studies, the NIRS records are performed off the MRI scan. Then, the input of the three dimensional coordinates of the optodes/channels is crucial for the reconstitution of the pictures. In the case of a co-record of NIRS and fMRI techniques, the coordinates of the NIRS optodes can be precisely assigned; else, skull measurements and probe placement are made either by reference to the 10-20 EEG system or by kinematic acquisition using such devices as optotrack or fastrack.

\subsection{Dos and don'ts}

Doubtlessly, the toughest part of the NIRS based studies, is to draw physiological and cognitive conclusions from the data. Multi-channel setups cover wide cortical zones and result in several time series and three dimensional coloured images in which probability to give statistically significant results is high. The question experimenters inevitably face is "What do those results mean?". A typical NIRS channel includes a great number of capillary 
beds, corresponding to a greater number of neurons (estimated around 300,000 to 500,000) from various depths in the cortex (Gervain et al., 2011). The pool of capillary beds enlighten by a channel is believed to belong to a given cortex area, which supposedly has a single function. This makes a huge simplification if compared to the brain complexity and its capacity of integration, not to mention the neuro-vascular coupling assumption (see part 4.1.)! Moreover, probe placement is based on the skull anatomy as no direct access to the brain is allowed by NIRS (except in the case of fMRI co-recording) giving a probability to fire over multiple cortex areas or even over a wrong area. Additionally, the proportion of excitatory and inhibitory neurons in the volume aimed by NIRS is unknown yet potentially affects the results.

\subsection{Confounding factors}

At this stage of the article, the most impeding factors have been brought to discussion. However, some factors, not directly linked to the NIRS concepts nor to brain characteristics must be debated. Before entering the tissue of interest, light travels through the skin and the fat layers (as well as the hair and skull layers in case of brain investigations, Fig. 3). The skin colour (and hair colour) has been shown to influence light absorption (Pringle et al., 1999). Intuitively, human eyes perceive various skin colours because skin absorbs and reflects light depending on its properties. The same (or the opposite) happens in the near infrared portion of the spectrum. Light skins are believed to absorb light more than dark skins, while Asian originated skins are the less absorbent. NIRS gain or laser power must then be modulated to fit with the skin properties of a given subject; which can be performed automatically by the NIRS hardware before starting the data acquisition.

Skin blood flow is one of the main confounding factors as the haemoglobin molecules present in the capillary beds located in the skin are the first (and last) exposed to NIRS light (Tew et al., 2010). In exercising subjects, blood flow is increasing in proportion to the intensity of exercise, for well-known thermoregulation reasons. However, skin is not believed to consume more oxygen at high intensity as compared with low intensity exercises. This means that skin blood flow overcomes by far the local metabolic demands; which necessarily biases the NIRS measurements.

The fat and bone layers are probably easier to take into account as they can be integrated in the automatic gain setup which occurs in most modern NIRS devices, before data acquisition.

Finally, gender has been shown to influence NIRS responses to various stimuli, notably motor, cognitive tasks and emotions (Marumo et al., 2009; Yang et al., 2009).

\section{Measuring the brain activities related to the motor stimulation using NIRS}

\subsection{Physiological processes associated with brain activity}

Physiological events associated with brain activity can be subdivided into intracellular events, events occurring at the cell membranes and those that are mediated by neurovascular coupling and occur within the vascular space. Increased brain activity is correlated not only with oxygen consumption but also with glucose consumption. The brain has only negligible stores of glucose and therefore relies both on the circulating glucose and on the active transport system which moves glucose across the blood-brain barrier. Increased activity in brain cells is associated with an increase in glucose consumption and 
thus the intracellular glucose concentration might fall in the early activation period (Villringer and Dirnagl, 1995). This transient drop in glucose is accompanied by a transient rise in local lactate concentration (Villringer and Dirnagl, 1995). Magistretti and Pellerin (Magistretti and Pellerin, 1999a, b) have provided new insights on the role of astrocytes in coupling neuronal activity with energy metabolism. They propose an initial glycolytic processing which occurs in astrocytes during activation, resulting in a transient lactate overproduction; followed by a recoupling phase during which lactate is oxidised by neurons. In addition to the events taking place intracellularly, local brain activity induces a local arteriolar vasodilation (Villringer and Dirnagl, 1995). Although small arteries and arterioles probably contain less than $5 \%$ of the blood volume in the brain parenchyma, they control most of the resistance and therefore blood flow at a local level. As a consequence of local vasodilation the local cerebral blood volume as well as the blood flow increase. This relationship between neuronal activity and vascular response is termed "neurovascular coupling". In other words, the changes in Hbtot most probably reflect the match between oxygen supply and oxygen demand, whereas changes in $\mathrm{O}_{2} \mathrm{Hb}$ reflect the alterations in cerebral blood flow, an overshoot in cerebral oxygenation during brain activation. Several NIRS studies conducted in the past fifteen years have demonstrated that activation- induced changes in brain activity can be assessed non-invasively during the performance of various whole-body motor activities (Maki et al., 1995; Obrig et al., 1996).

\subsection{Brain activity and motor performance}

The NIRS is applicable under a variety of conditions ranging from bedside monitoring in intensive care to documenting the effects of maximal whole body exercise in the physiology laboratory. To date, several studies have used NIRS to examine alterations in cerebral oxygenation during dynamic exercise, and have found an increase in cerebral oxygenation with medium and high-intensity exercise (Bhambhani et al., 2007; Shibuya et al., 2004a; Subudhi et al., 2007; Suzuki et al., 2004).

While a rather detailed understanding of brain activity during hand movement has been developed (Dettmers et al., 1995), less is known about the functional anatomy of motor control for leg or foot movements. Due to its advantages compared to other neuroimaging techniques, NIRS technique allows recording of cerebral activity during ordinary gait (Fig. 6). For instance, Miyai et al. (2001) were able to compare cerebral activities evoked during gait, alternating foot movements, arm swing and motor imagery of gait. Gait-related responses along the central sulcus were medial and caudal to activity associated with arm swing, in agreement with the known somatotopic organisation of the motor cortex (Perec, 1974). Crucially, these authors showed that walking increased cerebral activity bilaterally in the medial primary sensori-motor cortices and the supplementary motor area, and to a greater extent than the alternation of foot movements. Unfortunately, the spatial distribution and intensity of these responses were not statistically compared. In a different NIRS study, Suzuki et al. (2004) examined the effect of various walking speeds on cerebral activity. They demonstrated that cerebral activity in the prefrontal cortex and premotor cortex tended to increase as the locomotion speed increased, whereas cerebral activity in the medial sensorimotor cortex was not influenced by the locomotion speed. In summary, NIRS is particularly useful for studying the cortical bases of locomotion control. Unfortunately, given the limited depth penetration of the infrared light (a few centimetres from the skull surface), the NIRS 
technique can only assess the responses of the most superficial portions of the cerebral cortex.

Neuroimaging studies have reported a proportional relationship between cortical signals and exerted joint force in humans, indicating that brain signals are positively correlated to voluntary efforts, as a high level of effort is required for exerting greater muscle force (Liu et al., 2007; Liu et al., 2003). Recently several authors have proposed combining neuroimaging techniques with the classical twitch interpolation to investigate the central aspects of fatigue after and during ongoing exercise. Most studies on central fatigue have investigated isometric contractions of isolated muscle groups. Post et al. (2009) showed, during a sustained high force contraction, that the hemodynamic response (BOLD signal) in the most important motor (output) areas increased (primary sensorimotor cortex, supplementary motor area, premotor area), whereas the voluntary activation (accessed via the twitchinterpolation technique) of the index finger muscle during a unilateral task decreased with time. This finding suggests that although the central nervous system (CNS) increased its input to the motor areas, these increases did not overcome fatigue-related changes in the voluntary drive to the motor units. During a progressive maximal cycling exercise, Rupp and Perrey (2008) showed a decrease in prefrontal cortical oxygenation before motor performance failure, which may be compatible with the notion of a role for the prefrontal cortex in the reduction of motor output by the cessation of exercise. However, this finding was not associated with a decrease in voluntary activation, but measured 6 min postexercise. Support for the role of a failure of the CNS to excite the motor neurons adequately (i.e., central fatigue) in fatigue during challenging exercises has been provided by the finding that voluntary activation of skeletal muscles is reduced after fatiguing exercise.

This suboptimal muscle activation has also been functionally observed via lowered surface electromyographic (EMG) activity on several occasions during fatiguing exercises (MendezVillanueva et al., 2007). However, what triggers these acute changes in the CNS behaviour remains to be determined. Central fatigue may be elicited by low brain oxygenation, i.e., by insufficient $\mathrm{O}_{2}$ delivery and/or low pressure gradient to drive the diffusion of $\mathrm{O}_{2}$ from the capillaries to the mitochondria. Direct and indirect evidences support the contention that inadequate cerebral oxygenation depresses cortical neuron excitability, although the mechanisms remain debated (for review see Nybo and Rasmussen, 2007). The non-invasive technique of NIRS offers real-time measurement of oxygenation and hemodynamic responses in tissues, and thus, constitutes a relevant tool to enhance our current knowledge of central (CNS) and peripheral (muscle) determinants of whole-body exercise performance. Some studies have reported that muscle deoxygenation occurs during repeated cycling tests (Racinais et al., 2007). However, exercises of this nature appear to induce a fairly constant level of deoxygenation in prime mover muscles across repetitions, and therefore authors have suggested that muscle $\mathrm{O}_{2}$ uptake was well preserved and was not likely to represent a limiting factor. Data on cerebral oxygenation changes during fatiguing tests are currently presented in the literature. Based on studies conducted during constant workload exercise, incremental test to maximal effort (Rupp and Perrey, 2008), and supramaximal exercise (Shibuya et al., 2004b), the deoxygenation of the cerebral cortex has, in general, been incriminated in the cessation of exercise, or at least in the reduction of exercise intensity. This finding, however, is confounded by the availability of $\mathrm{O}_{2}$ (Subudhi et al., 2007). Although an association exists between cerebral oxygenation and performance in various 
exercises, no studies have yet determined if a critical level of cerebral deoxygenation impairs whole body exercise. Shibuya and colleagues Shibuya et al. (2004a) reported a progressive cerebral deoxygenation during intermittent exercises. Specifically, these authors observed a reduction in $\Delta\left[\mathrm{O}_{2} \mathrm{Hb}\right]$ and $\Delta[\mathrm{Hbtot}]$, while $\Delta[\mathrm{HHb}]$ increased, over the course of seven, 30s cycling exercises performed at an intensity corresponding to $150 \% \dot{\mathrm{V}} \mathrm{O}_{2}$ max and interspersed with $15 \mathrm{~s}$ of rest. It was concluded that fatigue, resulting from such intermittent supramaximal exercises, was related to a decrease in the cerebral oxygenation level.

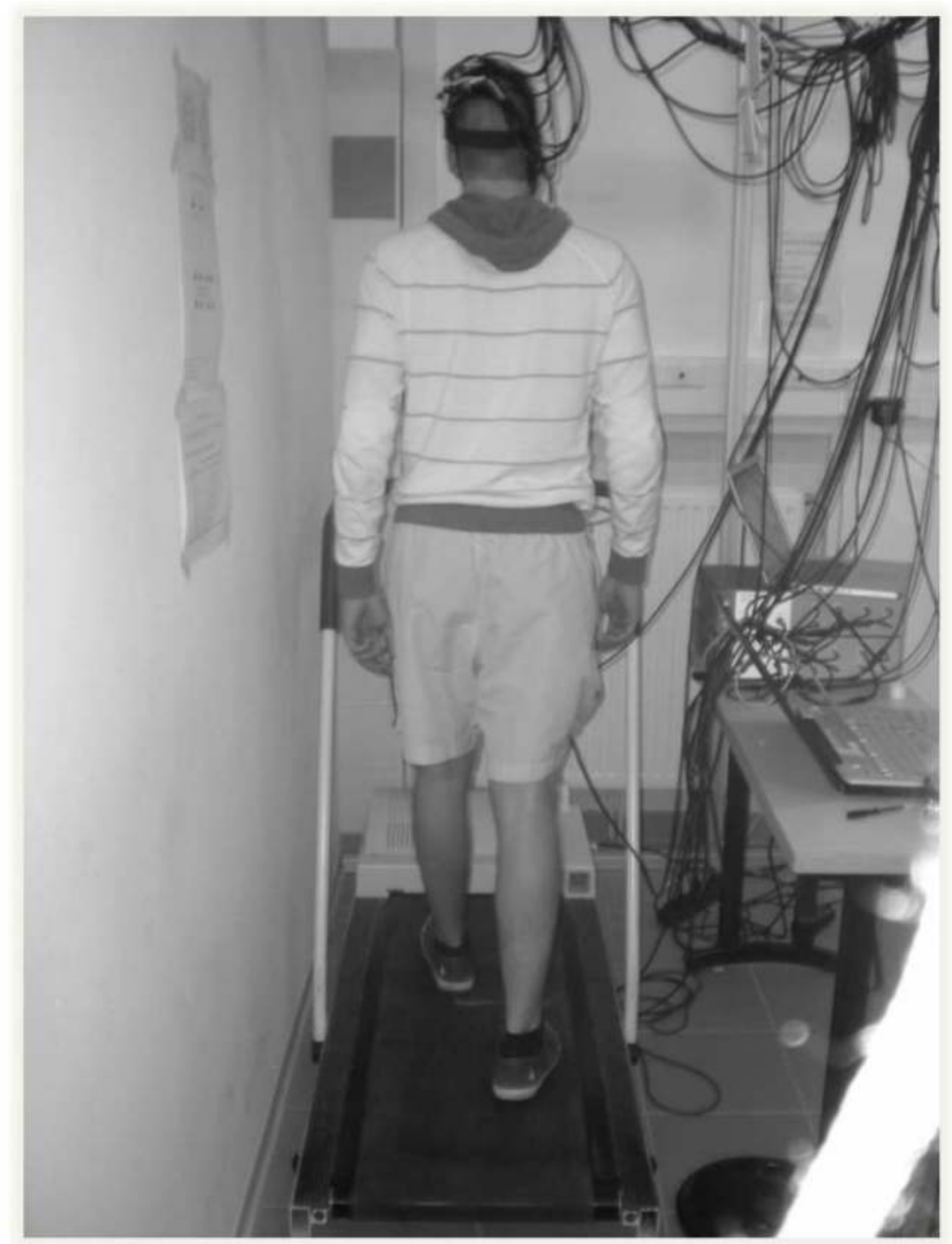

Fig. 6. Example of a NIRS setting while the subject is walking on a treadmill. 
To date based on recent evidences; we may propose that reductions in cerebral oxygenation during exhaustive intensities are caused by decreased cerebral blood flow coupled with increased cerebral oxygen uptake (Gonzalez-Alonso et al., 2004). It has also been proposed that this change in flow and metabolism at high intensities is sensed or controlled by a 'central governor' so that during oxygen availability reduction, peak exercise performance is reduced to prevent the development of ischemia in vital organs including the brain (Noakes et al., 2005). In this way, an increase in Hbtot and a decrease in cerebral oxygenation represent potential metabolic indicators, signalling either directly or indirectly to subcortical and cortical motor areas of the brain to reduce muscle unit recruitment and thus protect the brain and peripheral organs.

\section{Conclusion}

NIRS utilises light to measure cortical haemoglobin concentration changes associated with neural activity. This technique is more tolerant compared with other comparable techniques, regarding the subjects' movements, thus allowing a wider range of experimental tasks in the range of dynamic exercises. However, it has some shortcomings that need to be addressed. In this chapter, we showed how technical obstacles could be overcome, how NIRS contributes to the mapping of exercise-related brain functions, and further promotes the understanding of human movement and motor performance. In this context, we propose NIRS as a potential mediator between physiology and neuroscience. Beside these advances in technique and analysis of the data, we believe that users should consider the methodology's strengths and weakness when designing a NIRS study.

\section{References}

Avrillier, S., Tinet, E., Tualle, J.M., (1998a). Real time inversion using Monte Carlo results for the determination of absorption coefficients in multi-layered tissues: application to non invasive muscle oxymetry (Part 1), Munich.

Avrillier, S., Tinet, E., Tualle, J.M., Costes, F., Revel, F., Ollivier, J.P., (1998b). Real time inversion using Monte Carlo results for the determination of absorption coefficients in multi-layered tissues: application to non invasive muscle oxymetry (Part 2), Munich.

Beer, A., (1853). Einleitung in die höhere Optik. Druck und Verlag von Friedrich Vieweg und Sohn.

Bhambhani, Y., Malik, R., Mookerjee, S., (2007). Cerebral oxygenation declines at exercise intensities above the respiratory compensation threshold. Respir Physiol Neurobiol 156, 2, (May 14), pp. (196-202), ISSN 1569-9048 (Print) 1569-9048 (Linking).

Boas, D.A., Dale, A.M., Franceschini, M.A., (2004). Diffuse optical imaging of brain activation: approaches to optimizing image sensitivity, resolution, and accuracy. Neuroimage 23 Suppl 1, pp. (S275-288), ISSN 1053-8119.

Bouguer, P., (1729). Essais la gradation de la lumière. Claude Jombert, Paris, France.

Bourdillon, N., Mollard, P., Letournel, M., Beaudry, M., Richalet, J.P., (2009). Interaction between hypoxia and training on NIRS signal during exercise: contribution of a mathematical model. Respir Physiol Neurobiol 169, 1, (Oct 31), pp. (50-61). 
Broca, P., (2004). Ecrits sur l'aphasie (1861 - 1869). L'Harmattan, ISBN 2-7475-5925-4, Paris, France.

Cui, X., Bray, S., Bryant, D.M., Glover, G.H., Reiss, A.L., (2011). A quantitative comparison of NIRS and fMRI across multiple cognitive tasks. Neuroimage 54, 4, (Feb 14), pp. (2808-2821), ISSN 1095-9572 (Electronic) 1053-8119 (Linking).

Cui, X., Bray, S., Reiss, A.L., (2010a). Functional near infrared spectroscopy (NIRS) signal improvement based on negative correlation between oxygenated and deoxygenated hemoglobin dynamics. Neuroimage 49, 4, (Feb 15), pp. (3039-3046), ISSN 1095-9572 (Electronic) 1053-8119 (Linking).

Cui, X., Bray, S., Reiss, A.L., (2010b). Speeded near infrared spectroscopy (NIRS) response detection. PLoS One 5, 11, pp. (e15474), ISSN 1932-6203.

Dai, T.H., Liu, J.Z., Sahgal, V., Brown, R.W., Yue, G.H., (2001). Relationship between muscle output and functional MRI-measured brain activation. Exp Brain Res 140, 3, (Oct), pp. (290-300), ISSN 0014-4819.

Dettmers, C., Fink, G.R., Lemon, R.N., Stephan, K.M., Passingham, R.E., Silbersweig, D., Holmes, A., Ridding, M.C., Brooks, D.J., Frackowiak, R.S., (1995). Relation between cerebral activity and force in the motor areas of the human brain. J Neurophysiol 74, 2, (Aug), pp. (802-815), ISSN 0022-3077.

Duncan, A., Meek, J.H., Clemence, M., Elwell, C.E., Tyszczuk, L., Cope, M., Delpy, D.T., (1995). Optical pathlength measurements on adult head, calf and forearm and the head of the newborn infant using phase resolved optical spectroscopy. Phys Med Biol 40, 2, (Feb), pp. (295-304), ISSN 0031-9155.

Ekkekakis, P., (2009). Illuminating the black box: investigating prefrontal cortical hemodynamics during exercise with near-infrared spectroscopy. J Sport Exerc Psychol 31, 4, (Aug), pp. (505-553), ISSN 0895-2779.

Essenpreis, M., Cope, M., Elwell, C.E., Arridge, S.R., van der Zee, P., Delpy, D.T., (1993a). Wavelength dependence of the differential pathlength factor and the log slope in time-resolved tissue spectroscopy. Adv Exp Med Biol 333, pp. (9-20), ISSN 00652598.

Essenpreis, M., Elwell, C.E., Cope, M., van der Zee, P., Arridge, S.R., Delpy, D.T., (1993b). Spectral dependence of temporal point spread functions in human tissues. Appl Opt 32, 4, (Feb 1), pp. (418-425), ISSN 0003-6935.

Ferrante, S., Contini, D., Spinelli, L., Pedrocchi, A., Torricelli, A., Molteni, F., Ferrigno, G., Cubeddu, R., (2009). Monitoring muscle metabolic indexes by time-domain nearinfrared spectroscopy during knee flex-extension induced by functional electrical stimulation. J Biomed Opt 14, 4, (Jul-Aug), pp. (044011), ISSN 1560-2281 (Electronic) 1083-3668 (Linking).

Firbank, M., Hiraoka, M., Essenpreis, M., Delpy, D.T., (1993). Measurement of the optical properties of the skull in the wavelength range 650-950 nm. Phys Med Biol 38, 4, (Apr), pp. (503-510), ISSN 0031-9155.

Franceschini, M.A., Boas, D.A., (2004). Noninvasive measurement of neuronal activity with near-infrared optical imaging. Neuroimage 21, 1, (Jan), pp. (372-386), ISSN 10538119 . 
Friston, K.J., Holmes, A.P., Price, C.J., Buchel, C., Worsley, K.J., (1999). Multisubject fMRI studies and conjunction analyses. Neuroimage 10, 4, (Oct), pp. (385-396), ISSN 10538119.

Galvani, L., (1791). De viribus electricitatis in motu musculari commentarius. Bologna, Italy.

Gervain, J., Mehler, J., Werker, J.F., Nelson, C.A., Csibra, G., Lloyd-Fox, S., Shukla, M., Aslin, R.N., (2011). Near-infrared spectroscopy: A report from the McDonnell infant methodology consortium. Developmental Cognitive Neuroscience 1, 1, pp. (22-46).

Gonzalez-Alonso, J., Dalsgaard, M.K., Osada, T., Volianitis, S., Dawson, E.A., Yoshiga, C.C., Secher, N.H., (2004). Brain and central haemodynamics and oxygenation during maximal exercise in humans. J Physiol 557, Pt 1, (May 15), pp. (331-342), ISSN 00223751 (Print) 0022-3751 (Linking).

Harada, H., Tanaka, M., Kato, T., (2006). Brain olfactory activation measured by nearinfrared spectroscopy in humans. J Laryngol Otol 120, 8, (Aug), pp. (638-643), ISSN 1748-5460 (Electronic) 0022-2151 (Linking).

Hiraoka, M., Firbank, M., Essenpreis, M., Cope, M., Arridge, S.R., van der Zee, P., Delpy, D.T., (1993). A Monte Carlo investigation of optical pathlength in inhomogeneous tissue and its application to near-infrared spectroscopy. Phys Med Biol 38, 12, (Dec), pp. (1859-1876), ISSN 0031-9155.

Huppert, T.J., Diamond, S.G., Franceschini, M.A., Boas, D.A., (2009). HomER: a review of time-series analysis methods for near-infrared spectroscopy of the brain. Appl Opt 48, 10, (Apr 1), pp. (D280-298), ISSN 1539-4522 (Electronic) 0003-6935 (Linking).

Ijichi, S., Kusaka, T., Isobe, K., Okubo, K., Kawada, K., Namba, M., Okada, H., Nishida, T., Imai, T., Itoh, S., (2005). Developmental changes of optical properties in neonates determined by near-infrared time-resolved spectroscopy. Pediatr Res 58, 3, (Sep), pp. (568-573), ISSN 0031-3998.

Jantzen, K.J., Oullier, O., Scott Kelso, J.A., (2008). Neuroimaging coordination dynamics in the sport sciences. Methods 45, 4, (Aug), pp. (325-335), ISSN 1095-9130 (Electronic) 1046-2023 (Linking).

Kikukawa, A., Kobayashi, A., Miyamoto, Y., (2008). Monitoring of pre-frontal oxygen status in helicopter pilots using near-infrared spectrophotometers. Dyn Med 7, pp. (10), ISSN 1476-5918.

Koh, P.H., Glaser, D.E., Flandin, G., Kiebel, S., Butterworth, B., Maki, A., Delpy, D.T., Elwell, C.E., (2007). Functional optical signal analysis: a software tool for near-infrared spectroscopy data processing incorporating statistical parametric mapping. J Biomed Opt 12, 6, (Nov-Dec), pp. (064010), ISSN 1083-3668.

Kohl, M., Lindauer, U., Dirnagl, U., Villringer, A., (1998a). Separation of changes in light scattering and chromophore concentrations during cortical spreading depression in rats. Opt Lett 23, 7, (Apr 1), pp. (555-557), ISSN 0146-9592.

Kohl, M., Nolte, C., Heekeren, H.R., Horst, S., Scholz, U., Obrig, H., Villringer, A., (1998b). Determination of the wavelength dependence of the differential pathlength factor from near-infrared pulse signals. Phys Med Biol 43, 6, (Jun), pp. (1771-1782), ISSN 0031-9155.

Leff, D.R., Orihuela-Espina, F., Elwell, C.E., Athanasiou, T., Delpy, D.T., Darzi, A.W., Yang, G.Z., (2011). Assessment of the cerebral cortex during motor task behaviours in 
adults: a systematic review of functional near infrared spectroscopy (fNIRS) studies. Neuroimage 54, 4, (Feb 14), pp. (2922-2936), ISSN 1095-9572 (Electronic) 1053-8119 (Linking).

Liu, J.Z., Lewandowski, B., Karakasis, C., Yao, B., Siemionow, V., Sahgal, V., Yue, G.H., (2007). Shifting of activation center in the brain during muscle fatigue: an explanation of minimal central fatigue? Neuroimage 35, 1, (Mar), pp. (299-307), ISSN 1053-8119.

Liu, J.Z., Shan, Z.Y., Zhang, L.D., Sahgal, V., Brown, R.W., Yue, G.H., (2003). Human brain activation during sustained and intermittent submaximal fatigue muscle contractions: an FMRI study. J Neurophysiol 90, 1, (Jul), pp. (300-312), ISSN 00223077 (Print) 0022-3077 (Linking).

Lloyd-Fox, S., Blasi, A., Everdell, N., Elwell, C.E., Johnson, M.H., (2010). Selective Cortical Mapping of Biological Motion Processing in Young Infants. J Cogn Neurosci, (Oct 18), ISSN 1530-8898 (Electronic) 0898-929X (Linking).

Magistretti, P.J., Pellerin, L., (1999a). Astrocytes Couple Synaptic Activity to Glucose Utilization in the Brain. News Physiol Sci 14, (Oct), pp. (177-182), ISSN 0886-1714.

Magistretti, P.J., Pellerin, L., (1999b). Cellular mechanisms of brain energy metabolism and their relevance to functional brain imaging. Philos Trans $R$ Soc Lond B Biol Sci 354, 1387, (Jul 29), pp. (1155-1163), ISSN 0962-8436.

Maki, A., Yamashita, Y., Ito, Y., Watanabe, E., Mayanagi, Y., Koizumi, H., (1995). Spatial and temporal analysis of human motor activity using noninvasive NIR topography. Med Phys 22, 12, (Dec), pp. (1997-2005), ISSN 0094-2405.

Marumo, K., Takizawa, R., Kawakubo, Y., Onitsuka, T., Kasai, K., (2009). Gender difference in right lateral prefrontal hemodynamic response while viewing fearful faces: a multi-channel near-infrared spectroscopy study. Neurosci Res 63, 2, (Feb), pp. (8994), ISSN 0168-0102.

Matsuura, C., Gomes, P.S., Haykowsky, M., Bhambhani, Y., (2011). Cerebral and muscle oxygenation changes during static and dynamic knee extensions to voluntary fatigue in healthy men and women: a near infrared spectroscopy study. Clin Physiol Funct Imaging 31, 2, (Mar), pp. (114-123), ISSN 1475-097X (Electronic) 1475-0961 (Linking).

Mendez-Villanueva, A., Hamer, P., Bishop, D., (2007). Physical fitness and performance. Fatigue responses during repeated sprints matched for initial mechanical output. Med Sci Sports Exerc 39, 12, (Dec), pp. (2219-2225), ISSN 0195-9131.

Miyai, I., Tanabe, H.C., Sase, I., Eda, H., Oda, I., Konishi, I., Tsunazawa, Y., Suzuki, T., Yanagida, T., Kubota, K., (2001). Cortical mapping of gait in humans: a nearinfrared spectroscopic topography study. Neuroimage 14, 5, (Nov), pp. (1186-1192), ISSN 1053-8119.

Noakes, T.D., St Clair Gibson, A., Lambert, E.V., (2005). From catastrophe to complexity: a novel model of integrative central neural regulation of effort and fatigue during exercise in humans: summary and conclusions. Br J Sports Med 39, 2, (Feb), pp. (120-124), ISSN 1473-0480 (Electronic) 0306-3674 (Linking). 
Nolte, C., Kohl, M., Scholz, U., Weih, M., Villringer, A., (1998). Characterization of the pulse signal over the human head by near infrared spectroscopy. Adv Exp Med Biol 454, pp. (115-123), ISSN 0065-2598.

Nybo, L., Rasmussen, P., (2007). Inadequate cerebral oxygen delivery and central fatigue during strenuous exercise. Exerc Sport Sci Rev 35, 3, (Jul), pp. (110-118), ISSN 00916331 .

Obrig, H., Hirth, C., Junge-Hulsing, J.G., Doge, C., Wolf, T., Dirnagl, U., Villringer, A., (1996). Cerebral oxygenation changes in response to motor stimulation. J Appl Physiol 81, 3, (Sep), pp. (1174-1183), ISSN 8750-7587 (Print) 0161-7567 (Linking).

Peltonen, J.E., Paterson, D.H., Shoemaker, J.K., Delorey, D.S., Dumanoir, G.R., Petrella, R.J., Kowalchuk, J.M., (2009). Cerebral and muscle deoxygenation, hypoxic ventilatory chemosensitivity and cerebrovascular responsiveness during incremental exercise. Respir Physiol Neurobiol 169, 1, (Oct 31), pp. (24-35), ISSN 1878-1519 (Electronic) 1569-9048 (Linking).

Perec, G., (1974). Experimental demonstration of the tomatotopic organization in the Soprano (Cantatrix sopranica L.).

Pereira, M.I., Gomes, P.S., Bhambhani, Y.N., (2007). A brief review of the use of near infrared spectroscopy with particular interest in resistance exercise. Sports Med 37, 7, pp. (615-624), ISSN 0112-1642.

Perrey, S., (2008). Non-invasive NIR spectroscopy of human brain function during exercise. Methods 45, 4, (Aug), pp. (289-299), ISSN 1095-9130 (Electronic) 1046-2023 (Linking).

Plichta, M.M., Heinzel, S., Ehlis, A.C., Pauli, P., Fallgatter, A.J., (2007). Model-based analysis of rapid event-related functional near-infrared spectroscopy (NIRS) data: a parametric validation study. Neuroimage 35, 2, (Apr 1), pp. (625-634), ISSN 10538119.

Post, M., Steens, A., Renken, R., Maurits, N.M., Zijdewind, I., (2009). Voluntary activation and cortical activity during a sustained maximal contraction: an fMRI study. Hum Brain Mapp 30, 3, (Mar), pp. (1014-1027), ISSN 1097-0193 (Electronic) 1065-9471 (Linking).

Prahl, S., (2008). Tabulated molar extinction coefficient for hemoglobin in water. Values compiled using data provided by Gratzer WB, Medical Research Council Labs, Holly Hill London and Kollias N, Wellman laboratories, Harvard Medical School, Boston. http://omlc.ogi.edu/spectra/hemoglobin/summary.html.

Pringle, J., Roberts, C., Kohl, M., Lekeux, P., (1999). Near infrared spectroscopy in large animals: optical pathlength and influence of hair covering and epidermal pigmentation. Vet J 158, 1, (Jul), pp. (48-52), ISSN 1090-0233.

Racinais, S., Bishop, D., Denis, R., Lattier, G., Mendez-Villaneuva, A., Perrey, S., (2007). Muscle deoxygenation and neural drive to the muscle during repeated sprint cycling. Med Sci Sports Exerc 39, 2, (Feb), pp. (268-274), ISSN 0195-9131.

Rasmussen, P., Dawson, E.A., Nybo, L., van Lieshout, J.J., Secher, N.H., Gjedde, A., (2007). Capillary-oxygenation-level-dependent near-infrared spectrometry in frontal lobe of humans. J Cereb Blood Flow Metab 27, 5, (May), pp. (1082-1093), ISSN 0271-678X.

Rooks, C.R., Thom, N.J., McCully, K.K., Dishman, R.K., (2010). Effects of incremental exercise on cerebral oxygenation measured by near-infrared spectroscopy: a 
systematic review. Prog Neurobiol 92, 2, (Oct), pp. (134-150), ISSN 1873-5118 (Electronic) 0301-0082 (Linking).

Rupp, T., Perrey, S., (2008). Prefrontal cortex oxygenation and neuromuscular responses to exhaustive exercise. Eur J Appl Physiol 102, 2, (Jan), pp. (153-163), ISSN 1439-6327 (Electronic) 1439-6319 (Linking).

Schroeter, M.L., Bucheler, M.M., Muller, K., Uludag, K., Obrig, H., Lohmann, G., Tittgemeyer, M., Villringer, A., von Cramon, D.Y., (2004). Towards a standard analysis for functional near-infrared imaging. Neuroimage 21, 1, (Jan), pp. (283-290), ISSN 1053-8119.

Segal, S.S., (2005). Regulation of blood flow in the microcirculation. Microcirculation 12, 1, (Jan-Feb), pp. (33-45), ISSN 1073-9688.

Shibasaki, H., (2008). Human brain mapping: hemodynamic response and electrophysiology. Clin Neurophysiol 119, 4, (Apr), pp. (731-743), ISSN 1388-2457.

Shibuya, K., Tachi, M., (2006). Oxygenation in the motor cortex during exhaustive pinching exercise. Respir Physiol Neurobiol 153, 3, (Oct 27), pp. (261-266), ISSN 1569-9048.

Shibuya, K., Tanaka, J., Kuboyama, N., Murai, S., Ogaki, T., (2004a). Cerebral cortex activity during supramaximal exhaustive exercise. J Sports Med Phys Fitness 44, 2, (Jun), pp. (215-219), ISSN 0022-4707.

Shibuya, K., Tanaka, J., Kuboyama, N., Ogaki, T., (2004b). Cerebral oxygenation during intermittent supramaximal exercise. Respir Physiol Neurobiol 140, 2, (May 20), pp. (165-172), ISSN 1569-9048.

Simpson, C.R., Kohl, M., Essenpreis, M., Cope, M., (1998). Near-infrared optical properties of ex vivo human skin and subcutaneous tissues measured using the Monte Carlo inversion technique. Phys Med Biol 43, 9, (Sep), pp. (2465-2478), ISSN 0031-9155.

Smith, G.V., Alon, G., Roys, S.R., Gullapalli, R.P., (2003). Functional MRI determination of a dose-response relationship to lower extremity neuromuscular electrical stimulation in healthy subjects. Exp Brain Res 150, 1, (May), pp. (33-39), ISSN 0014-4819.

Subudhi, A.W., Dimmen, A.C., Roach, R.C., (2007). Effects of acute hypoxia on cerebral and muscle oxygenation during incremental exercise. J Appl Physiol 103, 1, (Jul), pp. (177-183), ISSN 8750-7587 (Print) 0161-7567 (Linking).

Suzuki, M., Miyai, I., Ono, T., Oda, I., Konishi, I., Kochiyama, T., Kubota, K., (2004). Prefrontal and premotor cortices are involved in adapting walking and running speed on the treadmill: an optical imaging study. Neuroimage 23, 3, (Nov), pp. (1020-1026), ISSN 1053-8119.

Swartz, B.E., Goldensohn, E.S., (1998). Timeline of the history of EEG and associated fields. Electroencephalogr Clin Neurophysiol 106, 2, (Feb), pp. (173-176), ISSN 0013-4694.

Tashiro, M., Itoh, M., Fujimoto, T., Masud, M.M., Watanuki, S., Yanai, K., (2008). Application of positron emission tomography to neuroimaging in sports sciences. Methods 45, 4, (Aug), pp. (300-306), ISSN 1095-9130 (Electronic) 1046-2023 (Linking).

Tew, G.A., Ruddock, A.D., Saxton, J.M., (2010). Skin blood flow differentially affects nearinfrared spectroscopy-derived measures of muscle oxygen saturation and blood volume at rest and during dynamic leg exercise. Eur J Appl Physiol 110, 5, (Nov), pp. (1083-1089), ISSN 1439-6327 (Electronic) 1439-6319 (Linking). 
Ultman, J.S., Piantadosi, C.A., (1991). Differential pathlength factor for diffuse photon scattering through tissue by a pulse-response method. Math Biosci 107, 1, (Nov), pp. (73-82), ISSN 0025-5564.

van der Zee, P., Cope, M., Arridge, S.R., Essenpreis, M., Potter, L.A., Edwards, A.D., Wyatt, J.S., McCormick, D.C., Roth, S.C., Reynolds, E.O., et al., (1992). Experimentally measured optical pathlengths for the adult head, calf and forearm and the head of the newborn infant as a function of inter optode spacing. Adv Exp Med Biol 316, pp. (143-153), ISSN 0065-2598.

Vesalius, A., (1543). De humani corporis fabrica. Brown University, Providence, Rhodes Island.

Villringer, A., (1997). Understanding functional neuroimaging methods based on neurovascular coupling. Adv Exp Med Biol 413, pp. (177-193), ISSN 0065-2598.

Villringer, A., Dirnagl, U., (1995). Coupling of brain activity and cerebral blood flow: basis of functional neuroimaging. Cerebrovasc Brain Metab Rev 7, 3, (Fall), pp. (240-276), ISSN 1040-8827.

Wernicke, C., (1894). Grundriss der Psychiatrie in klinischen Vorlesungen. Wrocław, Poland.

Wilcox, T., Bortfeld, H., Woods, R., Wruck, E., Boas, D.A., (2008). Hemodynamic response to featural changes in the occipital and inferior temporal cortex in infants: a preliminary methodological exploration. Dev Sci 11, 3, (May), pp. (361-370), ISSN 1467-7687 (Electronic) 1363-755X (Linking).

Wolf, M., Ferrari, M., Quaresima, V., (2007). Progress of near-infrared spectroscopy and topography for brain and muscle clinical applications. J Biomed Opt 12, 6, (NovDec), pp. (062104), ISSN 1083-3668.

Yang, H., Wang, Y., Zhou, Z., Gong, H., Luo, Q., Lu, Z., (2009). Sex differences in prefrontal hemodynamic response to mental arithmetic as assessed by near-infrared spectroscopy. Gend Med 6, 4, (Dec), pp. (565-574), ISSN 1878-7398 (Electronic) 15508579 (Linking).

Yasui, H., Takamoto, K., Hori, E., Urakawa, S., Nagashima, Y., Yada, Y., Ono, T., Nishijo, H., (2010). Significant correlation between autonomic nervous activity and cerebral hemodynamics during thermotherapy on the neck. Auton Neurosci 156, 1-2, (Aug 25), pp. (96-103), ISSN 1872-7484 (Electronic) 1566-0702 (Linking).

Ye, J.C., Tak, S., Jang, K.E., Jung, J., Jang, J., (2009). NIRS-SPM: statistical parametric mapping for near-infrared spectroscopy. Neuroimage 44, 2, (Jan 15), pp. (428-447), ISSN 1095-9572 (Electronic) 1053-8119 (Linking).

Zarahn, E., Aguirre, G.K., D'Esposito, M., (1997). Empirical analyses of BOLD fMRI statistics. I. Spatially unsmoothed data collected under null-hypothesis conditions. Neuroimage 5, 3, (Apr), pp. (179-197), ISSN 1053-8119.

Zhang, Q., Brown, E.N., Strangman, G.E., (2007a). Adaptive filtering for global interference cancellation and real-time recovery of evoked brain activity: a Monte Carlo simulation study. J Biomed Opt 12, 4, (Jul-Aug), pp. (044014), ISSN 1083-3668.

Zhang, Q., Brown, E.N., Strangman, G.E., (2007b). Adaptive filtering to reduce global interference in evoked brain activity detection: a human subject case study. $J$ Biomed Opt 12, 6, (Nov-Dec), pp. (064009), ISSN 1083-3668. 
Zhao, H., Tanikawa, Y., Gao, F., Onodera, Y., Sassaroli, A., Tanaka, K., Yamada, Y., (2002). Maps of optical differential pathlength factor of human adult forehead, somatosensory motor and occipital regions at multi-wavelengths in NIR. Phys Med Biol 47, 12, (Jun 21), pp. (2075-2093), ISSN 0031-9155. 


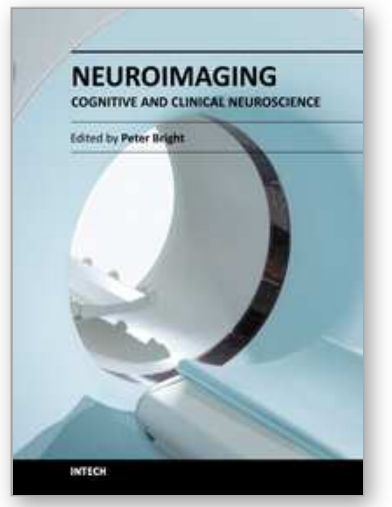

\author{
Neuroimaging - Cognitive and Clinical Neuroscience \\ Edited by Prof. Peter Bright
}

ISBN 978-953-51-0606-7

Hard cover, 462 pages

Publisher InTech

Published online 16, May, 2012

Published in print edition May, 2012

The rate of technological progress is encouraging increasingly sophisticated lines of enquiry in cognitive neuroscience and shows no sign of slowing down in the foreseeable future. Nevertheless, it is unlikely that even the strongest advocates of the cognitive neuroscience approach would maintain that advances in cognitive theory have kept in step with methods-based developments. There are several candidate reasons for the failure of neuroimaging studies to convincingly resolve many of the most important theoretical debates in the literature. For example, a significant proportion of published functional magnetic resonance imaging (fMRI) studies are not well grounded in cognitive theory, and this represents a step away from the traditional approach in experimental psychology of methodically and systematically building on (or chipping away at) existing theoretical models using tried and tested methods. Unless the experimental study design is set up within a clearly defined theoretical framework, any inferences that are drawn are unlikely to be accepted as anything other than speculative. A second, more fundamental issue is whether neuroimaging data alone can address how cognitive functions operate (far more interesting to the cognitive scientist than establishing the neuroanatomical coordinates of a given function - the where question).

\title{
How to reference
}

In order to correctly reference this scholarly work, feel free to copy and paste the following:

Nicolas Bourdillon and Stéphane Perrey (2012). What Does Cerebral Oxygenation Tell Us About Central Motor Output?, Neuroimaging - Cognitive and Clinical Neuroscience, Prof. Peter Bright (Ed.), ISBN: 978-953-510606-7, InTech, Available from: http://www.intechopen.com/books/neuroimaging-cognitive-and-clinicalneuroscience/what-does-cerebral-oxygenation-tell-us-about-central-motor-output

\section{INTECH}

open science | open minds

\section{InTech Europe}

University Campus STeP Ri

Slavka Krautzeka 83/A

51000 Rijeka, Croatia

Phone: +385 (51) 770447

Fax: +385 (51) 686166

www.intechopen.com

\section{InTech China}

Unit 405, Office Block, Hotel Equatorial Shanghai

No.65, Yan An Road (West), Shanghai, 200040, China 中国上海市延安西路65号上海国际贵都大饭店办公楼 405 单元

Phone: +86-21-62489820

Fax: +86-21-62489821 
(C) 2012 The Author(s). Licensee IntechOpen. This is an open access article distributed under the terms of the Creative Commons Attribution 3.0 License, which permits unrestricted use, distribution, and reproduction in any medium, provided the original work is properly cited. 